\title{
Performance of rapid test kits to assess household coverage of iodized salt
}

\author{
Jonathan Gorstein ${ }^{1, *}$, Frits van der Haar ${ }^{2}$, Karen Codling ${ }^{3}$, Robin Houston ${ }^{4}$, \\ Jacky Knowles ${ }^{5}$ and Arnold Timmer 5,6 \\ 'Department of Global Health, University of Washington, 60161 st Ave NW, Seattle, WA 98017, USA and lodine \\ Global Network: ${ }^{2}$ Emory University, Atlanta, GA, USA and lodine Global Network: ${ }^{3}$ Public Nutrition Solutions, \\ Bangkok, Thailand and lodine Global Network: ${ }^{4}$ Consultant, Bozeman, MT, USA: ${ }^{5}$ Global Alliance for Improved \\ Nutrition (GAIN), Geneva, Switzerland: ${ }^{\circ}$ UNICEF Ethiopia, Addis Ababa, Ethiopia
}

Submitted 25 September 2015: Final revision received 28 March 2016: Accepted 31 March 2016: First published online 11 May 2016

\begin{abstract}
Objective: The main indicator adopted to track universal salt iodization has been the coverage of adequately iodized salt in households. Rapid test kits (RTK) have been included in household surveys to test the iodine content in salt. However, laboratory studies of their performance have concluded that RTK are reliable only to distinguish between the presence and absence of iodine in salt, but not to determine whether salt is adequately iodized. The aim of the current paper was to examine the performance of RTK under field conditions and to recommend their most appropriate use in household surveys.

Design: Standard performance characteristics of the ability of RTK to detect the iodine content in salt at $0 \mathrm{mg} / \mathrm{kg}$ (salt with no iodine), $5 \mathrm{mg} / \mathrm{kg}$ (salt with any added iodine) and $15 \mathrm{mg} / \mathrm{kg}$ ('adequately' iodized salt) were calculated. Our analysis employed the agreement rate (AR) as a preferred metric of RTK performance.

Setting/Subjects: Twenty-five data sets from eighteen population surveys which assessed household iodized salt by both the RTK and a quantitative method (i.e. titration or WYD Checker) were obtained from Asian (nineteen data sets), African (five) and European (one) countries.

Results: In detecting iodine in salt at $0 \mathrm{mg} / \mathrm{kg}$, the RTK had an AR $>90 \%$ in eight of twenty-three surveys, while eight surveys had an AR $<80 \%$. When the RTK was used for detecting adequately iodized salt, the AR decreased significantly, with only one of fourteen surveys achieving an AR $>90 \%$.

Conclusions: The RTK is not suited for assessment of adequately iodized salt coverage. Quantitative assessment, such as by titration or WYD Checker, is necessary for estimates of adequately iodized salt coverage.
\end{abstract}

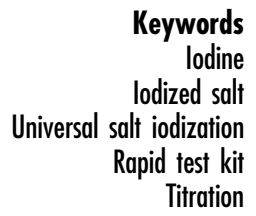

Iodine-deficiency disorders remain a widespread problem in many countries and iodine deficiency is the most preventable cause of brain damage globally ${ }^{(1)}$. Universal salt iodization (USI) is recommended by the WHO and UNICEF as the main strategy for the elimination of iodine-deficiency disorders because it is a safe, cost-effective and sustainable strategy to ensure sufficient intake of iodine by all individuals ${ }^{(2,3)}$. USI is achieved when all salt for human and livestock consumption, including salt used in the food industry, is adequately iodized $^{(4)}$ as this assures the entire population has access to enough iodine to meet their physiological requirements. Although household salt is only part of the intended total iodized salt supply, the presence (and adequacy of iodine) of salt in households has been widely adopted as a practical indicator for tracking the progress of USI strategies. According to international recommendations, household salt should contain at least $15 \mathrm{mg}$ iodine/ $\mathrm{kg}$ salt to be considered as 'adequately' iodized, and the target of $90 \%$ or more of households using adequately iodized salt has been designated for the achievement of $\mathrm{USI}^{(5)}$.

Estimates of the coverage of household iodized salt have been generated from many surveys since the mid-1990s. UNICEF maintains a database of the results from these surveys, which are published by country in the State of the World's Children reports each year and are posted on the UNICEF database website (http://data. unicef.org/nutrition/iodine). Since the World Summit on 
Children in 1990, during which countries committed to adopt USI, outstanding progress has been made around the world. UNICEF reports that the world coverage of households with 'adequately' iodized salt is currently $75 \%$, although this is only $50 \%$ for the least developed countries $^{(6,7)}$.

Simple rapid test kits (RTK) have been widely used in household coverage surveys, including the majority of surveys included in the global UNICEF database, to assess the presence and, in some cases, the adequacy of iodine in salt ${ }^{(8)}$. RTK are small $10-50 \mathrm{ml}$ bottles containing a stabilized starch/acid-based solution. When the solution is dropped on to a sample of salt containing iodine a blue/ purple stain develops, indicating the presence of iodine ${ }^{(9)}$. The intensity of the blue/purple colour indicates the approximate iodine concentration in the salt and colour charts have been developed to facilitate the 'reading' or classification of the approximate iodine content. Separate RTK have been developed to test for the presence of iodine either as potassium iodate or potassium iodide.

In view of the widespread use of RTK and the programmatic implications of the test results, it is important to determine whether RTK are sufficiently reliable to determine the level of iodine in salt quantitatively and, thus, are able to be used to track progress towards increasing access to an adequately iodized salt supply. Previous validation studies of the RTK in the laboratory against the 'gold standard' of iodometric titration concluded that RTK are accurate in distinguishing whether a salt sample is iodized or not, but perform less well in detecting the level of iodine quantitatively and, hence, in determining whether salt is adequately iodized ${ }^{(10,11)}$

To understand the reliability and accuracy of RTK under field conditions, the results of salt tests by an RTK in households should be compared with a validated quantitative laboratory method, such as titration or the WYD Checker ${ }^{(10-12)}$. The most widely used RTK manufactured by MBI Chemicals (India) was examined for validity against titration based on 3010 salt samples from four areas in India. The reported sensitivity of the kit was $89.8 \%$ and the specificity was $65.6 \%$, with an overall agreement rate of $92.9 \%{ }^{(13)}$.

The present paper examines the results of a series of household- and school-based surveys that tested the iodine content of household salt by RTK, as well as by either titration or WYD Checker. The purpose was to understand, under practical field conditions, the ability of the RTK to accurately detect: (i) salt with iodine; and (ii) salt that contains adequate iodine at the agreed-upon minimum for adequacy, namely $15 \mathrm{mg}$ iodine $/ \mathrm{kg}$ salt. The findings in the present paper complement existing RTK validation studies in the laboratory by providing additional results obtained under field conditions ${ }^{(14)}$. The RTK data were assessed for their ability to detect: (i) the absence/ presence of iodine in salt (i.e. household coverage of iodized salt); and (ii) salt iodized at $15 \mathrm{mg}$ iodine $/ \mathrm{kg}$ salt or greater (i.e. household coverage of adequately iodized salt). For the absence/presence of iodine, the analysis was undertaken using a cut-off at both $0 \mathrm{mg} / \mathrm{kg}$ and $5 \mathrm{mg} / \mathrm{kg}$. $5 \mathrm{mg} / \mathrm{kg}$ was used as a cut-off in recognition that raw salt may contain small amounts of iodine, considered to usually be less than $5 \mathrm{mg} / \mathrm{kg}^{(15)}$. A cut-off at $5 \mathrm{mg} / \mathrm{kg}$ would therefore help differentiate between salt that may naturally contain traces of iodine and salt that has actually been iodized and would be expected to have iodine content higher than $5 \mathrm{mg} / \mathrm{kg}$. It should be noted that the present paper did not attempt to tackle the objective of distinguishing salt samples with low levels of iodine as being naturally occurring iodine and/or iodine introduced in salt through iodization.

\section{Methods}

To obtain raw data from surveys that tested the iodine content of household salt by both RTK testing and a quantitative laboratory measurement (either WYD Checker or titration), a search was made by all of the present paper's authors with different organizations and agencies working in support of USI. The search yielded data of twenty-five surveys from eighteen countries: Armenia, Cambodia, Georgia, Ghana, India, Indonesia, Kazakhstan, Lao PDR, Malawi, Malaysia, Myanmar, Nepal, Philippines, Senegal, Tajikistan, Tanzania, Ukraine and Vietnam, from which approval and permission was received as summarized in Table 1 . While the search was extensive, it was opportunistic and not meant to be exhaustive. Results of only some of the surveys included in the analysis have been published. The current secondary analysis did not involve any individual identifiers and, as such, poses no ethical concerns. There was no consistent information on whether survey teams were trained on RTK use nor whether the RTK used were from the same production batch, both variables that may affect the quality of the RTK readings. The majority of the data sets in the present paper consisted of a sub-sample of salt specimens from all households enrolled in a survey that were subjected to quantitative analysis as well as RTK measures. Therefore, the coverage estimates reported herein may not always be the same as those cited in the official survey reports. There was information on the training and external quality assurance of quantitative analysis of the iodine content in salt from at least three of the surveys (Lao PDR 2006, Ghana 2015, Senegal 2014), but it was not clear about whether external quality assurance was implemented for others.

The principal statistical approach consisted of the construction of $2 \times 2$ tables and entering the number of RTK records for absence/presence $(>0 \mathrm{mg} / \mathrm{kg}$ and $>5 \mathrm{mg} / \mathrm{kg}$ ) and inadequate/adequate $(>15 \mathrm{mg} / \mathrm{kg})$ iodine against the respective quantitative data of titration or WYD Checker measurements. Estimates of population coverage were 
Table 1 Data sources for the present study

\begin{tabular}{|c|c|c|}
\hline Country & Year & Origin \\
\hline Armenia & 2005 & $\begin{array}{l}\text { Ministry of Health of Republic of Armenia and UNICEF. Report on results of the National Representative } \\
\text { Survey of lodine Nutrition and Implementation of Universal Salt lodization Program in Armenia, } 2005 . \\
\text { Published report. Data provided to authors by Armenia Ministry of Health }\end{array}$ \\
\hline Cambodia & 2008 & $\begin{array}{l}\text { The National Representative Survey of lodine Nutrition and Implementation of Universal Salt lodization } \\
\text { Program in Cambodia, Report of the National Sub-Committee for Control of IDD, Phnom Penh, } 2008 . \\
\text { Published report. Data provided to authors by UNICEF/Cambodia }\end{array}$ \\
\hline Cambodia & 2011 & $\begin{array}{l}\text { The National Representative Survey of lodine Nutrition and Implementation of Universal Salt lodization } \\
\text { Program in Cambodia, Report of the National Sub-Committee for Control of IDD, Phnom Penh, } 2011 . \\
\text { Published report. Data provided to authors by UNICEF/Cambodia }\end{array}$ \\
\hline Georgia & 2005 & $\begin{array}{l}\text { Suchdev PS, Jashi M, Sekhniashvili Z et al. (2009) Progress toward eliminating iodine deficiency in the } \\
\text { Republic of Georgia. Int J Endocrinol Metab 3, 200-207. Published report }\end{array}$ \\
\hline Ghana & $2009-10$ & $\begin{array}{l}\text { Food Fortification Survey } 2010 \text { (Ghana Health Services and GAIN). Data provided to authors by Ghana } \\
\text { Health Services }\end{array}$ \\
\hline Ghana & 2015 & $\begin{array}{l}2015 \text { National lodine Survey in Ghana (Ghana Health Services, GAIN and the Micronutrient Laboratory, } \\
\text { Department of Nutrition and Food Science, University of Ghana). Data provided to authors by Ghana } \\
\text { Health Services }\end{array}$ \\
\hline India (Delhi) & 2000 & Published report. Bulletin WHO paper ${ }^{(14)}$ \\
\hline India (MP) & 2000 & Published report. Bulletin WHO paper ${ }^{(14)}$ \\
\hline Indonesia & 2013 & $\begin{array}{l}\text { Badan Penelitian dan Pengembangan Kesehatan Kementerian Kesehatan Ri Tahun 2013. Riskesdas } \\
\text { 2013. Published report. }\end{array}$ \\
\hline Kazakhstan & 2006 & $\begin{array}{l}\text { WHO CAR News 2000, issue } 6,23 \text {. lodine deficiency in Central Asian Republics (in Russian). Data } \\
\text { provided to authors by Kazakh Academy of Nutrition }\end{array}$ \\
\hline Lao PDR & 2005 & $\begin{array}{l}\text { Ministry of Health and Ministry of Education. } 2005 \text { Nationwide School-based Survey. Data provided to } \\
\text { authors by UNICEF/Laos }\end{array}$ \\
\hline Lao PDR & 2006 & $\begin{array}{l}\text { National Maternal and Child Nutrition Survey (MICS3-NNS), The Lao PDR, 2006. Published report. Data } \\
\text { provided to authors by UNICEF/Laos }\end{array}$ \\
\hline Lao PDR & 2013 & $\begin{array}{l}\text { School-based survey of iodized salt use and status of iodine nutrition in Lao PDR, 2013. Data provided to } \\
\text { authors by UNICEF/Laos }\end{array}$ \\
\hline Malawi & 2006 & $\begin{array}{l}\text { Ministry of Health and Ministry of Education. } 2006 \text { National School Health and Nutrition Survey. Published } \\
\text { report. Data supplied by Ministry of Education, Science and Technology }\end{array}$ \\
\hline Malaysia & 2008 & $\begin{array}{l}\text { National IDD Survey: Selamat R, Mohamud WN, Zainuddin AA et al. (2010) lodine deficiency status and } \\
\text { iodized salt consumption in Malaysia: findings from a national iodine deficiency disorders survey. Asia } \\
\text { Pac J Clin Nutr 19, 578-585. Data provided by Ministry of Health, Malaysia, March } 2015\end{array}$ \\
\hline Myanmar & 2006 & $\begin{array}{l}\text { Ministry of Health. } 2006 \text { National Micronutrient Survey. Published report. Data provided by UNICEF/ } \\
\text { Myanmar }\end{array}$ \\
\hline Myanmar & 2011 & $\begin{array}{l}\text { Ministry of Health and UNICEF. Availability of lodised Salt at HH Level in Myanmar 2011: Report of a } \\
\text { School Based Survey. Published report. Data provided by UNICEF/Myanmar }\end{array}$ \\
\hline Nepal & 2005 & $\begin{array}{l}\text { Nepal IDD Status Survey } 2005 \text { (UNICEF and Micronutrient Initiative). Published report. Data provided to } \\
\text { authors by UNICEF/Nepal }\end{array}$ \\
\hline Nepal & 2013 & $\begin{array}{l}\text { Study of lodized Salt in Eastern Nepal (Central Institute of Science and Technology (CIST) College, } \\
\text { Pokhara University and B.P. Koirala Institute of Health Sciences. Published report }\end{array}$ \\
\hline Philippines & 2006 & FNRI Updating Survey 2005. Published report. Data provided to authors by UNICEF/Philippines \\
\hline Senegal & 2015 & $\begin{array}{l}2014 \text { National lodine Survey in Senegal. Cellule de Lutte contre la Malnutrition, Micronutrient Initiative, } \\
\text { GAIN and Laboratoire Chimie Analytique et Bromatologie, Faculté de Médecine et Pharmacie, } \\
\text { Université Cheikh Anta Diop. Data provided to authors by Cellule de Lutte contre la Malnutrition }\end{array}$ \\
\hline Tajikistan & 2007 & $\begin{array}{l}\text { State Committee on Statistics (Republic of Tajikistan) and UNICEF. 2009. Tajikistan living standards } \\
\text { measurement survey } 2007 \text { (TLSS): Indicators at a glance. Dushanbe, Tajikistan: State Committee on } \\
\text { Statistics and UNICEF. Published report. Data provided by UNICEF/Tajikistan }\end{array}$ \\
\hline Tanzania & 2010 & $\begin{array}{l}\text { National Bureau of Statistics - Ministry of Finance. Tanzania - Tanzania Demographic and Health Survey } \\
\text { 2010. Published report. Data provided to authors by Ministry of Health-Nutrition Division/Tanzania }\end{array}$ \\
\hline Ukraine & 2005 & $\begin{array}{l}\text { Achievement of the sustainable elimination of IDD by 2005. Conducted as a parallel study to the UNICEF/ } \\
\text { MICS. UNICEF Country Office Annual Report. Published report. Data supplied by UNICEF/Ukraine }\end{array}$ \\
\hline Vietnam & 2006 & $\begin{array}{l}2005 \text { National IDD Survey (UNICEF, Hanoi Endocrinology Hospital). Published report. Data provided to } \\
\text { authors by UNICEF/Vietnam }\end{array}$ \\
\hline
\end{tabular}

IDD, iodine-deficiency disorders; GAIN, Global Alliance for Improved Nutrition; MICS, Multiple Indicator Cluster Survey; HH, household.

calculated for each of the three cut-off points, along with $95 \%$ confidence interval estimates to determine whether differences in coverage by RTK and quantitative method were statistically significant. Comparisons of proportions were based on simple $\chi^{2}$ statistics. The test performance indicators included measures of sensitivity (Se), specificity $(\mathrm{Sp})$, predictive values (positive predictive value (PPV) and negative predictive value (NPV)) and accuracy (agreement rate (AR)) as described by Altman ${ }^{(16)}$. AR were based on the total number of true positive and true negative values divided by the total sample size and as such provided a composite measure of the accuracy of a test.

\section{Results}

Table 2 shows the basic characteristics of the surveys and methods used to assess household iodized salt. A total of 
Table 2 Basic characteristics of the rapid test kit (RTK) tests and methods used in the surveys in the present study $(n 25)$

\begin{tabular}{|c|c|c|c|c|c|}
\hline Country & Year & Type of RTK used & RTK coding system* & Quantitative method & Sample size \\
\hline Armenia & 2005 & $\mathrm{MBI}^{\mathrm{TM}}$ & B & Titration & 909 \\
\hline Cambodia & 2008 & $\mathrm{MBI}^{\mathrm{TM}}$ & A & Titration & 556 \\
\hline Cambodia & 2011 & $\mathrm{MBI}^{\mathrm{TM}}$ & A & Titration & 1275 \\
\hline Georgia & 2005 & $\mathrm{MBI}^{\mathrm{TM}}$ & $\mathrm{B}$ & Titration & 137 \\
\hline Ghana & $2009-10$ & $\mathrm{MBI}^{\mathrm{TM}}$ & $\mathrm{B}$ & Titration & 1206 \\
\hline Ghana & 2015 & $\mathrm{MBI}^{\mathrm{TM}}$ & B & Titration & 1560 \\
\hline India (Delhi) & 2000 & $\mathrm{MBI}^{\mathrm{TM}}$ & $\mathrm{B}$ & Titration & 1258 \\
\hline India (MP) & 2000 & $\mathrm{MBI}^{\mathrm{TM}}$ & $\mathrm{B}$ & Titration & 682 \\
\hline Indonesia & 2013 & $\mathrm{MBI}^{\mathrm{TM}}$ & $\mathrm{B}$ & Titration & 16804 \\
\hline Kazakhstan & 2006 & $\mathrm{MBI}^{\mathrm{TM}}$ & $\mathrm{B}$ & Titration & 1119 \\
\hline Lao PDR & 2005 & Thai I-Kit ${ }^{\mathrm{TM}}$ & A & WYD Checker & 2028 \\
\hline Lao PDR & 2006 & Thai I-Kit ${ }^{\mathrm{TM}}$ & $A$ & WYD Checker & 709 \\
\hline Lao PDR & 2013 & $\mathrm{MBI}^{\mathrm{TM}}$ & A & WYD Checker & 1006 \\
\hline Malawi & 2006 & $\mathrm{MBI}^{\mathrm{TM}}$ & A & Titration & 612 \\
\hline Malaysia & 2008 & $\mathrm{MBI}^{\mathrm{TM}}$ & $A$ & Titration & 1840 \\
\hline Myanmar & 2006 & $\mathrm{MBI}^{\mathrm{TM}}$ & C & WYD Checker & 394 \\
\hline Myanmar & 2011 & $\mathrm{MBI}^{\mathrm{TM}}$ & $\mathrm{C}$ & WYD Checker & 4198 \\
\hline Nepal & 2005 & $\mathrm{MBI}^{\mathrm{TM}}$ & B & Titration & 360 \\
\hline Nepal & 2013 & $\mathrm{MBI}^{\mathrm{TM}}$ & B & Titration & 360 \\
\hline Philippines & 2005 & $\mathrm{MBI}^{\mathrm{TM}}$ & A & WYD Checker & 3023 \\
\hline Senegal & 2015 & $\mathrm{MBI}^{\mathrm{TM}}$ & $\mathrm{B}$ & Titration & 1545 \\
\hline Tajikistan & 2007 & $\mathrm{MBI}^{\mathrm{TM}}$ & $\mathrm{B}$ & Titration & 1215 \\
\hline Tanzania & 2010 & $\mathrm{MBI}^{\mathrm{TM}}$ & B & Titration & 913 \\
\hline Ukraine & 2005 & $\mathrm{MBI}^{\mathrm{TM}}$ & $\mathrm{B}$ & Titration & 786 \\
\hline Vietnam & 2006 & $\mathrm{MBI}^{\mathrm{TM}}$ & A & Titration & 35529 \\
\hline
\end{tabular}

${ }^{*} \mathrm{~A}=$ not iodized/iodized; $\mathrm{B}=0,<15 \mathrm{ppm},>15$ ppm; $\mathrm{C}=0,7 \mathrm{ppm}, 15 \mathrm{ppm}, 30 \mathrm{ppm}$.

twenty-five surveys were included in the analysis from eighteen countries in South-East Asia, the Caucasus, Central Asia, West and East Africa, and Europe. The number of salt samples taken for comparison with WYD Checker/titration varied from 136 in Georgia to 35529 in Vietnam. Households were the primary sampling unit in most of the twenty-five surveys, while a small number of surveys (Lao PDR) visited schools to collect and test iodine in salt specimens. The RTK developed by MBI Chemicals, India (http://www.mbikits.com/the-mbi-kit/) was used in all of the surveys, except for the two surveys in the Lao PDR. Quantitative measurement of the iodine content in the salt samples was performed by standard titration in nineteen of the surveys, while the WYD Checker machine was employed in five others (three surveys in the Lao PDR, two surveys in Myanmar and one survey in the Philippines).

Use of the RTK varied in the different surveys. In nine surveys, the RTK were used only to indicate if the salt contained any iodine (colour) or not (no colour), while in fifteen surveys the RTK were used to categorize the salt as non-iodized salt (no colour), inadequately iodized salt (light blue colour 1 or $5-<15 \mathrm{mg} / \mathrm{kg}$ ) and adequately iodized salt (dark blue colour or $\geq 15 \mathrm{mg} / \mathrm{kg}$ ). In both of the Myanmar surveys, salt was categorized as being non-iodized $(0 \mathrm{mg} / \mathrm{kg})$ or as having $>7,15$ and $30 \mathrm{mg} / \mathrm{kg}$ using a differently designed RTK. While raw data were available for twenty-one surveys and subjected to analysis, this was not possible from others, for which only $2 \times 2$ cross-tabulations were available. Because of the differences in the way that the RTK were employed and the use of summary tables for quantitative data for some surveys which provided information only at either $0 \mathrm{mg} / \mathrm{kg}$ or a $5 \mathrm{mg} / \mathrm{kg}$ cut-off, the number of data points for analysis at the three cut-off points varied.

In all surveys, the quantitative measurements were assumed to provide the accurate results for salt iodine content. In this collection of surveys, information was not available on quality assurance procedures undertaken to ensure correct and reliable quantitative test results for all surveys.

\section{Comparison of coverage estimates}

RTK tests are conducted with the purpose of obtaining a 'coverage' estimate, i.e. the proportion of households using iodized salt and/or adequately iodized salt. In assessing how the RTK performed for this purpose, a first step was to analyse the extent to which the RTK coverage estimates were in agreement with those based on the quantitative results.

Tables 3 to 5 show that the RTK coverage estimates differed significantly from the estimates obtained by quantitative measurements in most of the surveys and at all three cut-off points. Significant differences occurred in the majority of estimates for iodized salt using cut-off points of both $0 \mathrm{mg} / \mathrm{kg}$ (eighteen of twenty-three) and $5 \mathrm{mg} / \mathrm{kg}$ (eleven of eighteen) to designate salt with some iodine, as well as at the cut-off point of $15 \mathrm{mg} / \mathrm{kg}$ (nine of fourteen) to designate adequately iodized salt. In estimates for iodized salt (i.e. salt with $>0$ or $>5 \mathrm{mg} / \mathrm{kg}$ ), the RTK significantly overestimated the true coverage in the Lao 
PDR (2013) and Nepal (2005) at the cut-off point of $0 \mathrm{mg} / \mathrm{kg}$, while in the other sixteen surveys where significant differences were found the RTK significantly underestimated the true coverage. However, the RTK led to higher coverage estimates in seven out of the eleven comparisons with a significant difference at the cut-off point of $5 \mathrm{mg} / \mathrm{kg}$. For the coverage estimates of adequately iodized salt, the RTK produced a higher coverage in seven out of the eight surveys with a significant difference between RTK and quantitative estimates. Overall, the RTK overestimated the true coverage at the $5 \mathrm{mg} / \mathrm{kg}$ and $15 \mathrm{mg} /$ $\mathrm{kg}$ cut-off points in the majority of surveys. On the other hand, the RTK tests tended to underestimate the true coverage at the $0 \mathrm{mg} / \mathrm{kg}$ cut-off, by as much as 53 percentage points in the Ghana survey.

\section{Rapid test kit performance characteristics}

The second step of the analysis was to assess RTK diagnostic performance using basic parameters of test Se and $\mathrm{Sp}$. The RTK performance in identifying salt with any iodine is given in Table 6. The RTK Se (the ability to identify true positives) for salt containing any iodine in the twenty-three surveys ranged from $40 \cdot 2 \%$ in Ghana (2009-10) to $99.7 \%$ in Armenia. The Se of the RTK to detect iodized salt was less than $90 \%$ in eleven of the twenty-three surveys, indicating that more than $10 \%$ of individual salt samples with a negative RTK result (i.e. indicating no iodine) were found to contain iodine by a quantitative method. The Sp of the RTK (the ability to identify true negatives) ranged from a low of $14.3 \%$ in India (MP) to $99 \cdot 6 \%$ in Cambodia (2011). The Sp was lower than $90 \%$ in eighteen of the twenty-three surveys.

Together, the Se and Sp of a test represent its diagnostic ability. Compared against the quantitative methods, the RTK correctly identified salt samples that contained any iodine (PPV) in more than $90 \%$ of all the surveys except in the Lao PDR (2013) and Ukraine surveys. The RTK performed much more poorly in identifying salt with no iodine (NPV), which was lower than $90 \%$ in twenty-two of the twenty-nine surveys. This implies a very high rate of false negatives, where salt samples were found to have no iodine when tested by RTK but did contain some iodine when analysed by a quantitative method.

A convenient way of illustrating the diagnostic ability of a test is to plot the Se of the test, which is the true positive rate (TPR) against the false positive rate (FPR), calculated as $1-\mathrm{Sp}$. The space encompassed by the TPR-FPR values is referred to as the 'receiver operating characteristic' (ROC), and the ideal diagnostic test would produce results that cluster in the upper left corner (100\% Se, 0\% FPR) of the ROC plot. Therefore, the closer the ROC values are clustered in the upper left corner, the better the overall performance of the diagnostic test. The ROC plot of the RTK ability to detect the presence of iodine in salt (cut-off at $0 \mathrm{mg} / \mathrm{kg}$ ) is shown in Fig. 1.

Table 3 Comparison of coverage estimates obtained by rapid test kit (RTK) testing and by quantitative measurement at $0 \mathrm{mg} / \mathrm{kg}$, using twenty-three data sets from population surveys which assessed household iodized salt by both the RTK and a quantitative method

\begin{tabular}{|c|c|c|c|c|c|c|}
\hline \multirow[b]{3}{*}{ Country } & \multicolumn{6}{|c|}{ Identify iodized salt (iodine $>0 \mathrm{mg} / \mathrm{kg}$ ) } \\
\hline & \multicolumn{2}{|c|}{$\begin{array}{c}\text { Coverage estimate: qualitative } \\
\text { RTK test }\end{array}$} & \multicolumn{2}{|c|}{$\begin{array}{l}\text { Coverage estimate: } \\
\text { quantitative measurement }\end{array}$} & \multicolumn{2}{|c|}{$\begin{array}{l}\text { Difference between } \\
\text { coverage estimates }\end{array}$} \\
\hline & $p_{\mathrm{RTK}}(\%)$ & $95 \% \mathrm{Cl}$ & $p_{\mathrm{LAB}}(\%)$ & $95 \% \mathrm{Cl}$ & $\%$ & Significance of difference \\
\hline Armenia & $97 \cdot 7$ & $96 \cdot 3,98 \cdot 7$ & $97 \cdot 7$ & $96 \cdot 3,98 \cdot 7$ & 0.0 & NS \\
\hline Cambodia (2008) & 74.1 & $70 \cdot 5,77 \cdot 7$ & 98.7 & $97.8,99 \cdot 6$ & -33.2 & $<0.05$ \\
\hline Cambodia (2011) & $66 \cdot 1$ & $63 \cdot 5,68 \cdot 7$ & $79 \cdot 1$ & $76 \cdot 9,81 \cdot 3$ & $-19 \cdot 7$ & $<0.05$ \\
\hline Georgia & 97.4 & $94.7,100 \cdot 0$ & $99 \cdot 3$ & $97.9,100 \cdot 0$ & $-2 \cdot 0$ & NS \\
\hline Ghana $(2009-10)$ & 38.2 & $35.5,40.9$ & 91.7 & $90 \cdot 1,93 \cdot 3$ & $-140 \cdot 1$ & $<0.05$ \\
\hline Ghana (2015) & 63.7 & $61 \cdot 3,66 \cdot 0$ & $99 \cdot 8$ & $99 \cdot 4,100 \cdot 0$ & $-56 \cdot 7$ & $<0.05$ \\
\hline India (Delhi) & 74.6 & $77 \cdot 2,77 \cdot 0$ & 99.5 & $99.1,99.9$ & -33.4 & $<0.05$ \\
\hline India (MP) & 93.0 & $91 \cdot 1,94 \cdot 9$ & 99.0 & $98.3,99.8$ & -6.5 & $<0.05$ \\
\hline Indonesia (2013) & $90 \cdot 8$ & $90 \cdot 4,91 \cdot 2$ & $99 \cdot 8$ & $99 \cdot 8,99 \cdot 8$ & -9.9 & $<0.05$ \\
\hline Kazakhstan & $97 \cdot 0$ & $96 \cdot 0,98 \cdot 0$ & $97 \cdot 3$ & $96 \cdot 3,98 \cdot 3$ & -0.3 & NS \\
\hline Lao PDR (2005) & $78 \cdot 2$ & $76 \cdot 4,80 \cdot 0$ & 98.5 & $98 \cdot 0,99 \cdot 0$ & $-26 \cdot 0$ & $<0.05$ \\
\hline Lao PDR (2013) & $86 \cdot 1$ & $84 \cdot 0,88 \cdot 2$ & $67 \cdot 1$ & $64 \cdot 2,70 \cdot 0$ & $22 \cdot 1$ & $<0.05$ \\
\hline Malawi & $92 \cdot 3$ & $90 \cdot 2,94.4$ & $91 \cdot 2$ & $89 \cdot 0,93 \cdot 4$ & 1.2 & NS \\
\hline Myanmar (2006) & $86 \cdot 8$ & $84.6,89.0$ & $99 . \overline{6}$ & $99.2,100 \cdot 0$ & $-14 . \overline{7}$ & $<0.05$ \\
\hline Myanmar (2011) & 92.4 & $91 \cdot 9,92 \cdot 9$ & $98 \cdot 8$ & $98 \cdot 6,99 \cdot 0$ & $-6 \cdot 9$ & $<0.05$ \\
\hline Nepal (2005) & 93.6 & $91.9,95 \cdot 3$ & $86 \cdot 9$ & $84 \cdot 6,89 \cdot 2$ & $7 \cdot 2$ & $<0.05$ \\
\hline Nepal (2013) & 98.2 & $97 \cdot 6,98 \cdot 8$ & 99.9 & $99.8,100.0$ & $-1 \cdot \overline{7}$ & $<0.05$ \\
\hline Philippines & 79.2 & $78 \cdot 2,80 \cdot 2$ & $96 \cdot 9$ & $96 \cdot 5,97 \cdot 3$ & $-22 \cdot 3$ & $<0.05$ \\
\hline Senegal (2015) & $70 \cdot 0$ & $67 \cdot 7,72 \cdot 3$ & 99.5 & $99.1,99.8$ & $-42 \cdot 1$ & $<0.05$ \\
\hline Tanzania & 80.5 & $79 \cdot 0,82 \cdot 0$ & $87 \cdot 1$ & $85 \cdot 9,88 \cdot 3$ & $-8 \cdot 2$ & $<0.05$ \\
\hline Tajikistan & 87.5 & $86 \cdot 1,88 \cdot 9$ & 85.0 & $83 \cdot 5,86 \cdot 5$ & 2.9 & NS \\
\hline Ukraine & $42 \cdot 9$ & $40 \cdot 6,45 \cdot 2$ & $53 \cdot 6$ & $51 \cdot 3,55 \cdot 9$ & -24.9 & $<0.05$ \\
\hline Vietnam & $94 \cdot 3$ & $94 \cdot 1,94.5$ & $97 \cdot 3$ & $97 \cdot 2,97 \cdot 4$ & $-3 \cdot 2$ & $<0.05$ \\
\hline
\end{tabular}

n 23.

Table includes prevalence estimates and $95 \%$ confidence intervals. Differences between coverage estimates from methods were compared using $X^{2}$ tests. 
Table 4 Comparison of coverage estimates obtained by rapid test kit (RTK) testing and by quantitative measurement at $5 \mathrm{mg} / \mathrm{kg}$, using eighteen data sets from population surveys which assessed household iodized salt by both the RTK and a quantitative method

\begin{tabular}{|c|c|c|c|c|c|c|}
\hline \multirow[b]{3}{*}{ Country } & \multicolumn{6}{|c|}{ Identify iodized salt (iodine $>5 \mathrm{mg} / \mathrm{kg}$ ) } \\
\hline & \multicolumn{2}{|c|}{$\begin{array}{c}\text { Coverage estimate: qualitative RTK } \\
\text { test }\end{array}$} & \multicolumn{2}{|c|}{$\begin{array}{c}\text { Coverage estimate: quantitative } \\
\text { measurement }\end{array}$} & \multicolumn{2}{|c|}{$\begin{array}{c}\text { Difference between coverage } \\
\text { estimates }\end{array}$} \\
\hline & $p_{\mathrm{RTK}}(\%)$ & $95 \% \mathrm{Cl}$ & $p_{\mathrm{LAB}}(\%)$ & $95 \% \mathrm{Cl}$ & $\%$ & Significance of difference \\
\hline Cambodia (2008) & $74 \cdot 1$ & $70 \cdot 2,77 \cdot 7$ & $72 \cdot 1$ & $68.4,75 \cdot 8$ & $2 \cdot 7$ & NS \\
\hline Cambodia (2011) & $66 \cdot 1$ & $63 \cdot 5,68 \cdot 7$ & 66.5 & $63 \cdot 9,69 \cdot 1$ & -0.6 & NS \\
\hline Ghana (2015) & 63.7 & $61 \cdot 3,66 \cdot 1$ & $62 \cdot 0$ & $59 \cdot 6,64 \cdot 4$ & $2 \cdot 7$ & NS \\
\hline Indonesia (2013) & $90 \cdot 8$ & $90 \cdot 4,91 \cdot 2$ & $92 \cdot 3$ & $91 \cdot 9,92 \cdot 7$ & $-1 \cdot 7$ & $<0.05$ \\
\hline Kazakhstan & 97.0 & $96 \cdot 0,98 \cdot 0$ & $96 \cdot 6$ & $95 \cdot 5,97 \cdot 7$ & 0.4 & NS \\
\hline Lao PDR (2005) & 78.2 & $76 \cdot 4,80.0$ & 91.7 & $90.5,92.9$ & $-17 \cdot 3$ & $<0.05$ \\
\hline Lao PDR (2006) & $82 \cdot 8$ & $80 \cdot 0,88 \cdot 2$ & $97 \cdot 0$ & $95 \cdot 7,98 \cdot 3$ & $-17 \cdot 1$ & $<0.05$ \\
\hline Lao PDR (2013) & $86 \cdot 1$ & $84.0,88.2$ & 58.9 & $55.9,61.9$ & 31.6 & $<0.05$ \\
\hline Malawi & $92 \cdot 3$ & $90 \cdot 2,94.4$ & $76 \cdot 3$ & $72 \cdot 9,79 \cdot 7$ & $17 \cdot 3$ & $<0.05$ \\
\hline Malaysia & 33.0 & $30 \cdot 9,35 \cdot 2$ & $20 \cdot 8$ & $18 \cdot 9,22 \cdot 7$ & $37 \cdot 0$ & $<0.05$ \\
\hline Myanmar (2006) & 86.8 & $84.6,89.0$ & 83.2 & $80 \cdot 8,85 \cdot 6$ & 4.1 & NS \\
\hline Myanmar (2011) & 92.4 & $91.9,92 \cdot 9$ & 81.5 & $80 \cdot 7,82 \cdot 3$ & 11.8 & $<0.05$ \\
\hline Philippines & 79.2 & $78 \cdot 2,80 \cdot 2$ & 66.7 & $65 \cdot 6,67 \cdot 8$ & $15 \cdot 8$ & $<0.05$ \\
\hline Senegal (2015) & $70 \cdot 1$ & $67 \cdot 8,72 \cdot 4$ & 81.2 & $79 \cdot 2,83 \cdot 2$ & $-15 \cdot 8$ & $<0.05$ \\
\hline Tanzania & 80.5 & $79 \cdot 0,82 \cdot 0$ & $65 \cdot 9$ & $64 \cdot 2,67 \cdot 6$ & $18 \cdot 1$ & $<0.05$ \\
\hline Tajikistan & 87.5 & $86 \cdot 1,88.9$ & $82 \cdot 3$ & $80 \cdot 7,83.9$ & 5.9 & $<0.05$ \\
\hline Ukraine & $42 \cdot 9$ & $40 \cdot 6,45 \cdot 2$ & $42 \cdot 0$ & $39.7,44 \cdot 3$ & $2 \cdot 1$ & NS \\
\hline Vietnam & $94 \cdot 3$ & $94 \cdot 1,94 \cdot 5$ & 95.9 & $95 \cdot 8,96 \cdot 0$ & -1.7 & NS \\
\hline
\end{tabular}

$n 18$.

Table includes prevalence estimates and $95 \%$ confidence intervals. Differences between coverage estimates from methods were compared using $x^{2}$ tests.

Table 5 Comparison of coverage estimates obtained by rapid test kit (RTK) testing and by quantitative measurement at $15 \mathrm{mg} / \mathrm{kg}$, using fourteen data sets from population surveys which assessed household iodized salt by both the RTK and a quantitative method

\begin{tabular}{|c|c|c|c|c|c|c|}
\hline \multirow[b]{3}{*}{ Country } & \multicolumn{6}{|c|}{ Identify adequately iodized salt (iodine $>15 \mathrm{mg} / \mathrm{kg}$ ) } \\
\hline & \multicolumn{2}{|c|}{$\begin{array}{c}\text { Coverage estimate: qualitative RTK } \\
\text { test }\end{array}$} & \multicolumn{2}{|c|}{$\begin{array}{l}\text { Coverage estimate: quantitative } \\
\text { measurement }\end{array}$} & \multicolumn{2}{|c|}{$\begin{array}{c}\text { Difference between coverage } \\
\text { estimates }\end{array}$} \\
\hline & $p_{\text {RTK }}(\%)$ & $95 \% \mathrm{Cl}$ & $p_{\mathrm{LAB}}(\%)$ & $95 \% \mathrm{Cl}$ & $\%$ & Significance of difference \\
\hline Georgia & 93.8 & $89.8,97.8$ & 93.8 & $89 \cdot 8,97 \cdot 8$ & 0.0 & NS \\
\hline Ghana (2009-10) & 21.4 & $19 \cdot 1,23 \cdot 7$ & 48.2 & $45.4,51.0$ & $-125 \cdot 2$ & $<0.05$ \\
\hline Ghana (2015) & $42 \cdot 4$ & $40 \cdot 0,44.9$ & $29 \cdot 3$ & $27 \cdot 0,31 \cdot 6$ & 30.9 & $<0.05$ \\
\hline India (Delhi) & 63.6 & $60 \cdot 1,66 \cdot 3$ & 64.5 & $61 \cdot 9,67 \cdot 1$ & -1.4 & NS \\
\hline India (MP) & 83.4 & $80 \cdot 6,86.2$ & 69.5 & $66.0,73.0$ & $16 \cdot 7$ & $<0.05$ \\
\hline Indonesia (2013) & $76 \cdot 8$ & $76 \cdot 2,77 \cdot 4$ & $55 \cdot 2$ & $54.5,55.9$ & $28 \cdot 1$ & $<0.05$ \\
\hline Kazakhstan & 92.0 & $90.4,93.6$ & 86.4 & $84.4,88.4$ & $6 \cdot 1$ & $<0.05$ \\
\hline Myanmar (2006) & 71.5 & $68.6,74.4$ & $52 \cdot 3$ & $49 \cdot 1,55 \cdot 5$ & $26 \cdot 9$ & $<0.05$ \\
\hline Myanmar (2011) & 72.9 & $72 \cdot 0,73 \cdot 8$ & 33.4 & $32 \cdot 5,34 \cdot 3$ & $54 \cdot 2$ & $<0.05$ \\
\hline Nepal (2005) & 66.9 & $63 \cdot 7,70 \cdot 1$ & 67.2 & $64 \cdot 0,70 \cdot 4$ & -0.4 & NS \\
\hline Nepal (2013) & $75 \cdot 5$ & $73.4,77 \cdot 6$ & $82 \cdot 6$ & $80 \cdot 8,84.4$ & -9.4 & $<0.05$ \\
\hline Tanzania & $60 \cdot 2$ & $58 \cdot 4,62 \cdot 0$ & $59 \cdot 6$ & $57 \cdot 8,61 \cdot 4$ & 1.0 & NS \\
\hline Tajikistan & $77 \cdot 2$ & $75.4,78.9$ & 44.4 & $42 \cdot 3,46 \cdot 5$ & 42.5 & $<0.05$ \\
\hline Ukraine & 31.8 & $29 \cdot 7,33.9$ & $32 \cdot 1$ & $30.0,34.2$ & -0.9 & NS \\
\hline
\end{tabular}

$n 14$.

Table includes prevalence estimates and $95 \%$ confidence intervals. Differences between coverage estimates from methods were compared using $x^{2}$ tests.

Figure 1 illustrates that the RTK performance in detecting salt with any iodine (cut-off at $0 \mathrm{mg} / \mathrm{kg}$ ) is situated along a mostly horizontal TPR band with Se $\geq 75 \%$. Although the Se was high, the very high percentage of false negatives detected by the RTK gave a very different impression of the proportion of household salt that contained any iodine by a quantitative analysis. The Ghana data point stands out with Se of only $40 \%$.
To examine whether there was an improved performance of the RTK to detect salt with very low levels of iodine, either through extremely poor salt iodization or naturally occurring iodine in salt, the performance of RTK was recalculated for eighteen surveys where quantitative estimates for the percentage of salt specimens with iodine $<5 \mathrm{mg} / \mathrm{kg}$ were available. The results of these calculations are shown in Table 7 and Fig. 2. 
Table 6 Basic rapid test kit (RTK) diagnostic performance indices in tests for iodized salt at $0 \mathrm{mg} / \mathrm{kg}^{\star}$, using twenty-three data sets from population surveys which assessed household iodized salt by both the RTK and a quantitative method

\begin{tabular}{|c|c|c|c|c|}
\hline & Sensitivity (Se) & Specificity (Sp) & Positive predictive value (PPV) & Negative predictive value (NPV) \\
\hline Armenia & 99.7 & $97 \cdot 6$ & 99.9 & $97 \cdot 6$ \\
\hline Cambodia (2008) & 74.9 & $85 \cdot 7$ & 99.8 & 4.2 \\
\hline Cambodia (2011) & 83.5 & $99 \cdot 6$ & 99.9 & $61 . \overline{6}$ \\
\hline Georgia & $97 \cdot 8$ & 50.0 & $99 \cdot 6$ & $14 \cdot 3$ \\
\hline Ghana (2009-10) & $40 \cdot 2$ & 84.0 & $96 \cdot 5$ & 11.3 \\
\hline Ghana (2015) & 63.6 & 33.3 & 99.8 & 0.2 \\
\hline India (Delhi) & 74.9 & $92 \cdot 3$ & 99.9 & 1.9 \\
\hline India (MP) & 93.0 & $14 \cdot 3$ & 99.1 & $2 \cdot 1$ \\
\hline Indonesia 2013) & $90 \cdot 8$ & 25.8 & 99.8 & 0.5 \\
\hline Kazakhstan & 99.5 & $96 \cdot 7$ & 99.9 & $85 \cdot 3$ \\
\hline Lao PDR (2005) & $79 \cdot 3$ & 98.3 & $100 \cdot 0$ & 6.5 \\
\hline Lao PDR (2013) & $98 \cdot 1$ & 31.8 & 76.4 & 88.0 \\
\hline Malawi & 93.4 & 18.5 & 92.2 & 21.3 \\
\hline Myanmar (2006) & 87.0 & $66 \cdot 7$ & 99.9 & 1.9 \\
\hline Myanmar (2011) & 93.1 & 64.0 & 99.5 & $10 \cdot 1$ \\
\hline Nepal (2005) & $97 \cdot 1$ & 29.8 & $90 \cdot 2$ & 60.9 \\
\hline Nepal (2013) & $98 \cdot 3$ & 50.0 & 99.9 & 4.0 \\
\hline Philippines & 80.9 & $76 \cdot 6$ & $99 \cdot 1$ & 11.4 \\
\hline Senegal (2015) & $70 \cdot 3$ & 87.5 & 99.9 & 1.5 \\
\hline Tanzania & 86.6 & 60.5 & 93.7 & 40.1 \\
\hline Tajikistan & $92 \cdot 9$ & $43 \cdot 1$ & $90 \cdot 2$ & 51.8 \\
\hline Ukraine & $70 \cdot 1$ & 88.5 & 87.5 & 71.9 \\
\hline Vietnam & $96 \cdot 4$ & 82.4 & 99.5 & 38.7 \\
\hline
\end{tabular}

*Values below $90 \%$ are highlighted.

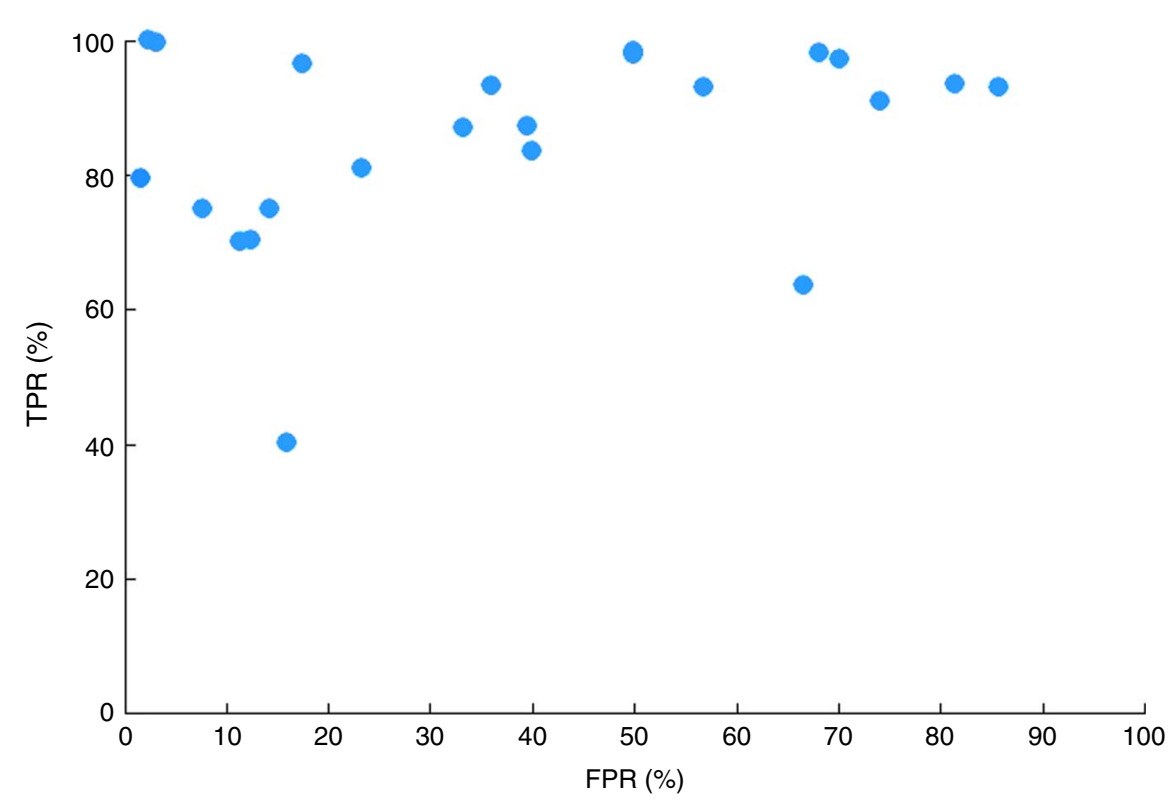

Fig. 1 (colour online) Diagnostic ability of the rapid test kit (RTK) in identifying non-iodized salt $(0 \mathrm{mg} / \mathrm{kg})$ using twenty-three data sets from population surveys which assessed household iodized salt by both the RTK and a quantitative method (TPR, true positive rate; FPR, false positive rate)

The revised cut-point for the classification of salt with any iodine from $0 \mathrm{mg} / \mathrm{kg}$ to $5 \mathrm{mg} / \mathrm{kg}$ did not greatly improve overall performance, and had opposite effects on the Se and Sp. As would be expected, Se increased for all of the surveys, most markedly in Cambodia (2008) from 74.9 to $95 \cdot 5$, Ghana (2015) from 63.6 to 83.2 , the Philippines from $80 \cdot 9$ to $97 \cdot 3$ and Ukraine from $70 \cdot 1$ to $84 \cdot 2$.
With the revised cut-off point at $5 \mathrm{mg} / \mathrm{kg}$, Se reached $\geq 90 \%$ in thirteen of the eighteen surveys. The change of cut-point to $5 \mathrm{mg} / \mathrm{kg}$ led to a decrease in Sp (Table 7), which was particularly dramatic in Kazakhstan from 96.7 to $81 \cdot 6$, Myanmar (2011) from $64 \cdot 0$ to $24 \cdot 3$ and the Philippines from $76 \cdot 6$ to $57 \cdot 3$. As expected, the increases in Se were accompanied by decreases in overall PPV and higher 
Table 7 Basic rapid test kit (RTK) performance indices in tests for iodized salt at $5 \mathrm{mg} / \mathrm{kg}^{*}$, using eighteen data sets from population surveys which assessed household iodized salt by both the RTK and a quantitative method

\begin{tabular}{|c|c|c|c|c|}
\hline & Sensitivity (Se) & Specificity (Sp) & Positive predictive value (PPV) & Negative predictive value (NPV) \\
\hline Cambodia (2008) & 95.5 & 81.3 & 93.0 & 87.5 \\
\hline Cambodia (2013) & $96 \cdot 8$ & 94.8 & $97 \cdot 4$ & 93.8 \\
\hline Ghana (2015) & 83.2 & 68.3 & 81.1 & 71.4 \\
\hline Indonesia (2013) & 92.5 & 29.9 & $94 \cdot 1$ & 24.9 \\
\hline Kazakhstan & 99.7 & 81.6 & 99.4 & $91 \cdot 2$ \\
\hline Lao PDR (2005) & 85.0 & $97 \cdot 6$ & $99 \cdot 7$ & 37.2 \\
\hline Lao PDR (2006) & 84.4 & 71.4 & $99 \cdot 0$ & $12 \cdot 3$ \\
\hline Lao PDR (2013) & $98 \cdot 1$ & 25.5 & 67.2 & 89.8 \\
\hline Malawi & $94 \cdot 2$ & 13.8 & 77.9 & 42.6 \\
\hline Malaysia & 94.8 & 83.2 & 59.6 & 98.4 \\
\hline Myanmar (2006) & $96 \cdot 0$ & 59.1 & $92 \cdot 1$ & $75 \cdot 0$ \\
\hline Myanmar (2011) & $96 \cdot 3$ & $24 \cdot 3$ & 84.8 & 59.6 \\
\hline Philippines & $97 \cdot 3$ & $57 \cdot 3$ & 82.0 & 91.4 \\
\hline Senegal & 77.6 & 62.8 & $90 \cdot 0$ & $36 \cdot 3$ \\
\hline Tanzania & 94.3 & $46 \cdot 1$ & 77.2 & 80.6 \\
\hline Tajikistan & 93.1 & 38.3 & 87.5 & 54.4 \\
\hline Ukraine & 84.2 & 87.1 & 82.5 & 88.4 \\
\hline Vietnam & $97 \cdot 7$ & 84.7 & 99.3 & 61.6 \\
\hline
\end{tabular}

*Values below $90 \%$ are highlighted.

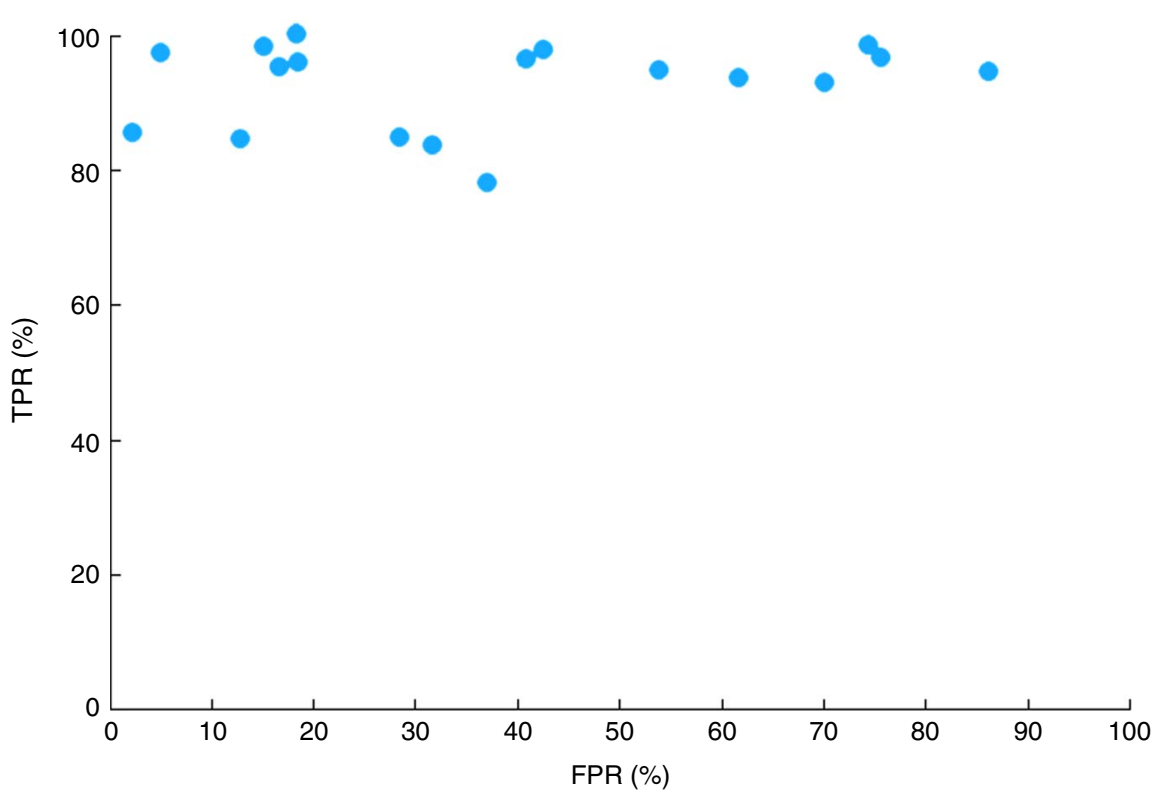

Fig. 2 (colour online) Diagnostic ability of the rapid test kit (RTK) in identifying iodized salt (5 mg/kg) using eighteen data sets from population surveys which assessed household iodized salt by both the RTK and a quantitative method (TPR, true positive rate; FPR, false positive rate)

NPV, suggesting that a high proportion of salt samples testing positive by RTK were those containing $<5 \mathrm{mg} / \mathrm{kg}$ iodine.

The present study also assessed the diagnostic performance of the RTK in detecting adequately iodized salt, i.e. salt with iodine content $>15 \mathrm{mg} / \mathrm{kg}$. The true coverage of adequately iodized salt in these surveys, based on quantitative methods, varied from $29.8 \%$ in Ghana (2015) to $93.8 \%$ in Georgia. The findings of RTK performance at the $15 \mathrm{mg} / \mathrm{kg}$ cut-point are summarized in Table 8 and Fig. 3.

The RTK test for adequately iodized salt achieved high Se in India (MP and Delhi), Kazakhstan and Myanmar
(2006 and 2011), with lowest Se values noted in Ghana (2009-10), Tanzania and Ukraine. The Sp of the tests for adequately iodized salt was above $90 \%$ in only three out of fourteen surveys (Ghana (2009-10), India (Delhi) and Ukraine), but quite low in all others. Particularly striking were the lower PPV and NPV in several of the comparisons relative to those which assessed the performance of RTK to detect salt with any iodine $(0 \mathrm{mg} / \mathrm{kg})$, which suggests a less robust diagnostic RTK proficiency in distinguishing salt that contains iodine content $>15 \mathrm{mg} / \mathrm{kg}$ than its ability to differentiate salt samples with no iodine. 
Table 8 Basic rapid test kit (RTK) performance indices in tests for adequately iodized salt at $15 \mathrm{mg} / \mathrm{kg}^{*}$, using fourteen data sets from population surveys which assessed household iodized salt by both the RTK and a quantitative method

\begin{tabular}{|c|c|c|c|c|}
\hline & Sensitivity (Se) & Specificity (Sp) & Positive predictive value (PPV) & Negative predictive value (NPV) \\
\hline Georgia & $93 \cdot 8$ & 5.9 & $93 \cdot 8$ & 5.9 \\
\hline Ghana $(2009-10)$ & 39.9 & $95 \cdot 8$ & 89.9 & 63.2 \\
\hline Ghana (2015) & 85.4 & 75.4 & $59 \cdot 1$ & 92.5 \\
\hline India (Delhi) & 93.3 & $90 \cdot 4$ & 94.6 & 88.2 \\
\hline India (MP) & 93.9 & 40.4 & 78.2 & $74 \cdot 3$ \\
\hline Indonesia (2013) & 89.6 & 38.9 & $64 \cdot 3$ & $75 \cdot 2$ \\
\hline Kazakhstan & $95 \cdot 8$ & $32 \cdot 2$ & $90 \cdot 0$ & 54.4 \\
\hline Myanmar (2006) & $99 \cdot 8$ & 59.6 & 73.0 & $99 \cdot 6$ \\
\hline Myanmar (2011) & $90 \cdot 2$ & $35 \cdot 7$ & 41.3 & 87.9 \\
\hline Nepal (2005) & $80 \cdot 2$ & 60.2 & 80.5 & 59.7 \\
\hline Nepal (2013) & 84.8 & 68.3 & $92 \cdot 7$ & 48.6 \\
\hline Tanzania & $65 \cdot 1$ & $46 \cdot 8$ & $64 \cdot 3$ & 47.6 \\
\hline Tajikistan & 83.0 & 27.5 & $47 \cdot 7$ & 67.0 \\
\hline Ukraine & 78.2 & $90 \cdot 1$ & 78.8 & $89 \cdot 7$ \\
\hline
\end{tabular}

*Values below $90 \%$ are highlighted.

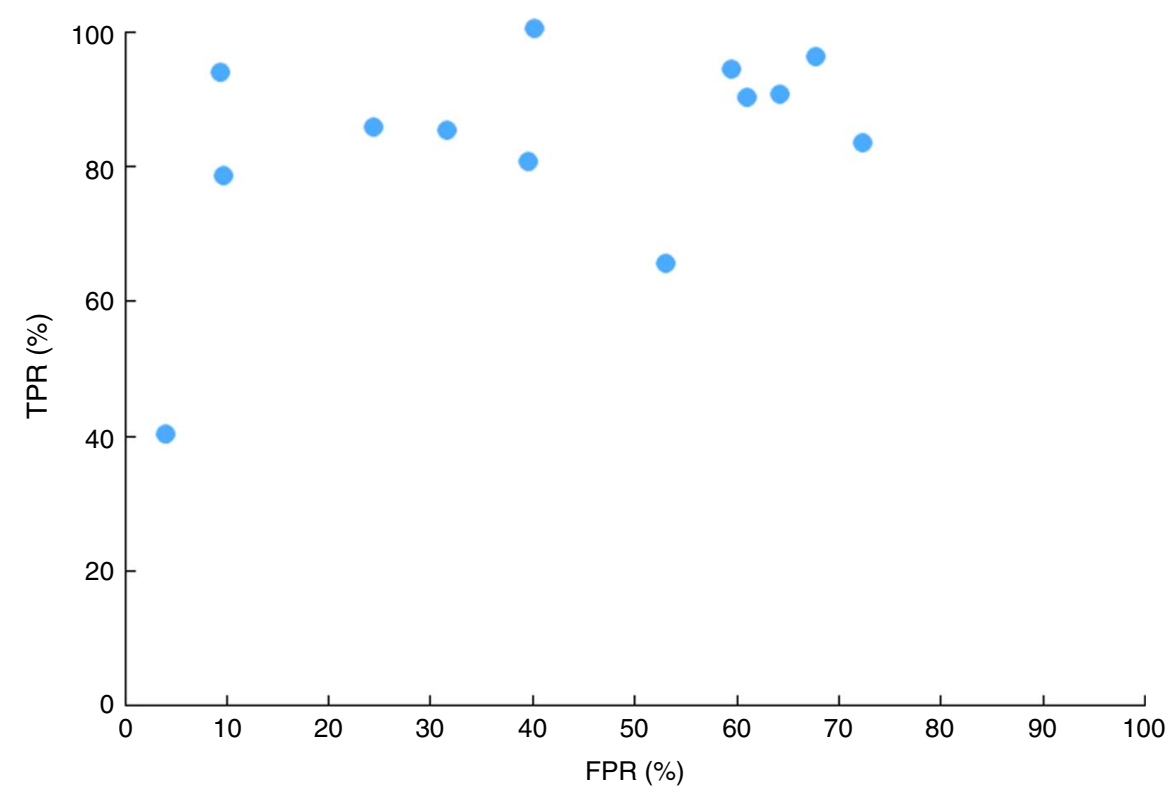

Fig. 3 (colour online) Diagnostic ability of the rapid test kit (RTK) in identifying adequately iodized salt (15 mg/kg) using fourteen data sets from population surveys which assessed household iodized salt by both the RTK and a quantitative method (TPR, true positive rate; FPR, false positive rate)

\section{Accuracy of rapid test kit testing for iodized salt and adequately iodized salt}

The findings presented up to this point have focused on the diagnostic proficiency of the RTK test, assessed by the occurrence of misclassification - i.e. the false positive and false negative RTK tests. A third step was to calculate the overall accuracy or AR of RTK performance. The AR was calculated for each of the surveys at the three cut-off points (according to available data) and the results are presented in Table 9.

Table 9 and Fig. 4 illustrate that the RTK was accurate in classifying $\geq 90 \%$ of all salt samples tested in eight out of the twenty-three surveys at $0 \mathrm{mg} / \mathrm{kg}$. The increase of cut-off point for iodized salt from $0 \mathrm{mg} / \mathrm{kg}$ to $5 \mathrm{mg} / \mathrm{kg}$ had variable effects on the accuracy. AR increased in eight of the sixteen surveys for which both sets of data were available, but decreased in the eight others. Despite this increase, however, the $\mathrm{AR}$ at $5 \mathrm{mg} / \mathrm{kg}$ reached $>90 \%$ in only four out of eighteen surveys. When using the RTK for detecting adequately iodized salt, the AR showed relative proportional decreases of up to $72 \%$ as compared with $0 \mathrm{mg} / \mathrm{kg}$. Only one survey (India (Delhi)) achieved an accuracy of $>90 \%$ with the use of the RTK test to detect adequately iodized salt.

\section{Discussion}

RTK have been used in many field surveys to estimate the household coverage of iodized salt and adequately iodized salt to track the performance of USI programmes. It is therefore important to obtain accurate information 
Table 9 Accuracy of rapid test kit (RTK) tests in detecting iodine in salt at 0,5 and $15 \mathrm{mg} / \mathrm{kg}^{*}$, using respectively twenty-three, eighteen and fourteen data sets from population surveys which assessed household iodized salt by both the RTK and a quantitative method

\begin{tabular}{|c|c|c|c|}
\hline & \multicolumn{3}{|c|}{ Accuracy (agreement rate, AR) } \\
\hline & $0 \mathrm{mg} / \mathrm{kg}(\%)$ & $5 \mathrm{mg} / \mathrm{kg}(\%)$ & $15 \mathrm{mg} / \mathrm{kg}(\%)$ \\
\hline Armenia & 99.9 & & \\
\hline Cambodia (2008) & 75.0 & 91.5 & \\
\hline Cambodia (2011) & 86.9 & $96 \cdot 2$ & \\
\hline Georgia & 97.4 & & 88.3 \\
\hline Ghana (2009-10) & 43.9 & & 68.9 \\
\hline Ghana (2015) & 63.6 & 77.6 & 78.3 \\
\hline India (Delhi) & 75.0 & & $92 \cdot 3$ \\
\hline India (MP) & 92.2 & & 77.0 \\
\hline Indonesia (2013) & $90 \cdot 7$ & 87.7 & 66.9 \\
\hline Kazakhstan & 99.5 & 99.1 & $87 \cdot 1$ \\
\hline Lao PDR (2005) & 79.6 & $86 \cdot 1$ & \\
\hline Lao PDR (2008) & & $84 \cdot 1$ & \\
\hline Lao PDR (2013) & $75 \cdot 2$ & 67.5 & \\
\hline Malawi & 86.8 & $75 \cdot 2$ & \\
\hline Malaysia & & 85.6 & \\
\hline Myanmar (2006) & 86.9 & 89.8 & 80.6 \\
\hline Myanmar (2011) & $92 \cdot 8$ & 82.9 & 54.0 \\
\hline Nepal (2005) & 88.3 & & 73.6 \\
\hline Nepal (2013) & $98 \cdot 2$ & & 81.9 \\
\hline Philippines & 80.8 & 84.0 & \\
\hline Senegal & 70.4 & 74.8 & \\
\hline Tanzania & 83.2 & 77.9 & $57 \cdot 7$ \\
\hline Tajikistan & 85.4 & 83.4 & 52.1 \\
\hline Ukraine & 78.6 & 85.9 & $86 \cdot 3$ \\
\hline Vietnam & $96 \cdot 1$ & $97 \cdot 2$ & \\
\hline
\end{tabular}

AR were based on the total number of true positive and true negative values divided by the total sample size and as such provided a composite measure of the accuracy of a test.

*Values below $90 \%$ are highlighted.

from the use of this tool. Although laboratory comparisons using quantitative methods have indicated that RTK are not able to produce reliable estimates of adequately iodized salt ${ }^{(17)}$, few efforts have been undertaken to verify this finding under 'real life' conditions of field surveys. The present study analysed a series of surveys which measured the iodine content in salt by both RTK and quantitative methods with the ultimate aim of developing recommendations on their most appropriate use.

The use of RTK to assess iodized salt in households was first adopted in the UNICEF Multiple Indicator Cluster Surveys (MICS) during the 1990s and have since been included in many Demographic and Health Surveys (DHS) and other household-based surveys. A 'USI Monitoring Manual' published in 1995 included specific recommendations which encouraged the use of RTK to determine the quality of salt iodization at the point of production, retail and consumption ${ }^{(9)}$. The manual promoted the fact that the kits were 'simple, rapid, and easily applied in field settings' and suggested that one of the advantages was that they were particularly appropriate when quantitative laboratory titration methods were not available.

In household surveys, the RTK is used to obtain a visual indication of the presence of iodine in salt for two principal purposes, namely: (i) indicating whether iodine (in any amount) is present in salt; and (ii) discerning whether the amount of iodine in salt is adequate. Because iodine in salt produces a specific colour reaction with starch, a false reading under the first purpose is difficult to imagine when the test is carried out correctly. Therefore, in assessing the performance of RTK to measure the presence of iodine in salt, the occurrence of false positive readings is expected to be low. The most common RTK manufactured include colour charts which reflect the concentration of iodine: the darker the colour, the higher the iodine content in salt. However, implementing this step requires training and objectivity, which has often been limited in the use of RTK in practice. Thus, it was expected that the RTK would yield better performance for identifying the presence of any iodine in salt during field surveys than for discerning whether the amount of iodine in salt was adequate. This reasoning was in line with the findings of laboratory-based studies, and our overall analysis confirmed these observations. The performance indicators were considerably more favourable for the RTK test results to identify iodized salt than adequately iodized salt. The Se, PPV and AR of the RTK test results were more likely to reach $\geq 90 \%$ at 0 or $5 \mathrm{mg} / \mathrm{kg}$ than at $15 \mathrm{mg} / \mathrm{kg}$.

For assessments of the RTK's overall diagnostic ability, the AR was used as a recommended composite measure of Se and $\mathrm{Sp}^{(16)}$; setting the AR at the $90 \%$ level for minimally acceptable RTK performance to detect salt with no iodine $(0 \mathrm{mg} / \mathrm{kg})$ or salt with adequate iodine $(15 \mathrm{mg} / \mathrm{kg})$. Acknowledging that the $90 \%$ limit for acceptable 

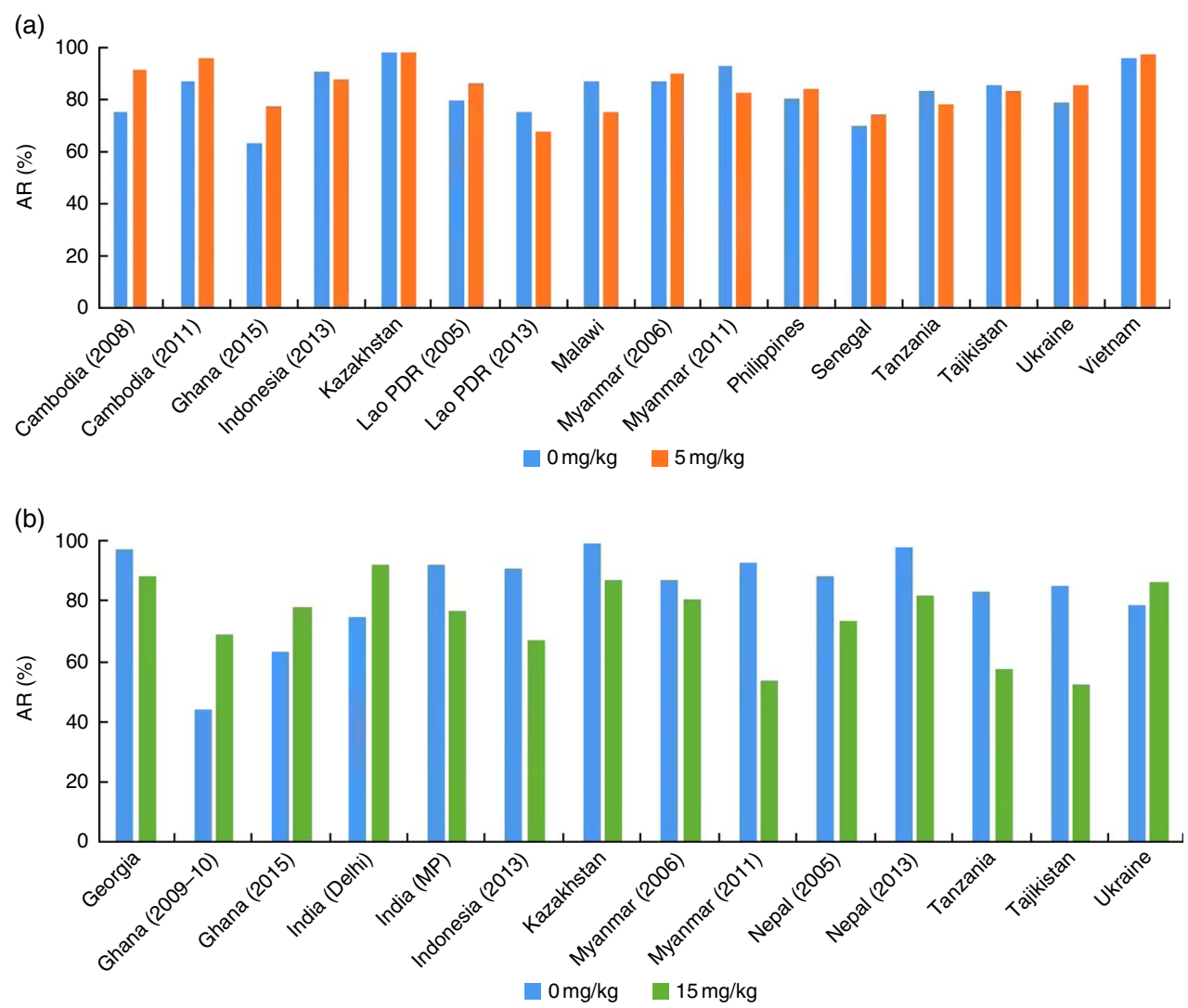

Fig. 4 (colour online) Agreement rates (AR) between the rapid test kit (RTK) and quantitative methods in identifying non-iodized salt $(0 \mathrm{mg} / \mathrm{kg})$, iodized salt $(5 \mathrm{mg} / \mathrm{kg})$ and adequately iodized salt $(15 \mathrm{mg} / \mathrm{kg})$ using data from sixteen (a) or fourteen (b) data sets from population surveys which assessed household iodized salt by both the RTK and a quantitative method: (a) $0 \mathrm{mg} / \mathrm{kg} v$. $5 \mathrm{mg} / \mathrm{kg}$; (b) $0 \mathrm{mg} / \mathrm{kg}$ v. $15 \mathrm{mg} / \mathrm{kg}$

performance is essentially arbitrary, it nevertheless proved valuable to expose the sizeable difference that exists in RTK performance between tests for any iodized salt and for adequately iodized salt.

The ROC plot, which informs on the Se and Sp data pairs from each survey separately, is a useful summary tool for diagnostic tests ${ }^{(18)}$. In contrast to the AR, which combines the Se and Sp information in a single measure, the bivariate ROC plot retains the two-dimensional nature of the original data and thereby permits a joint inspection of Se and Sp, making it easier for separate effects on Se and Sp to become apparent. In our analysis, Figs 1 and 3 clearly demonstrated that the poor performance of the RTK under field conditions at the cut-off points of $0 \mathrm{mg} / \mathrm{kg}$ and $15 \mathrm{mg} / \mathrm{kg}$ was driven mostly by the many false positive test outcomes.

The finding from the ROC plots of the poor RTK performance in Ghana strongly suggests a dissimilarity of the salt physical properties and/or unique conduct of the RTK tests in the Ghana survey. Despite a number of discussions with survey experts and professionals in the salt enterprise sector (who reported similar experiences with the RTK) and the food control authority in Ghana, no satisfactory explanation for these unusual findings was found.
When the RTK is used for obtaining a visual estimation of the amount of iodine present in salt, the assessment of the intensity of the colour generated by the test involves a value judgement by the observer, which is more likely prone to error and is also a function of grain size and salt quality. Nevertheless, it seems that, because the RTK test is simple, rapid and easily applied in the field by individuals without specialized training, its practicality has outweighed a lack of accuracy.

A number of factors affect the analysis of iodine in salt using RTK. These include the level of training of field enumerators, who are often not oriented on the use of RTK, and standardization exercises to minimize different readings between measurers' variation are not typically done. The characteristics of salt (e.g. moisture content, particle size, etc.) may affect RTK performance in which colour reaction is sometimes fast and then fades, while other times the reaction is slow, thereby affecting readings. RTK can detect iodine added as either potassium iodate or potassium iodide but if the wrong kit is used, a colour reaction may not occur. A colour reaction may also not occur if the salt is very alkaline. A re-check solution is provided to address this, but it is not often used or is applied incorrectly. Finally, there are operational and 
supply management issues with the RTK. The shelf-life and stability of the kits is stated to be 2 years, and poor logistics and distribution may lead to the use of expired kits.

There was limited information available on the quality control procedures of the laboratories used to undertake the quantitative analysis of the iodine content in salt. While this may have affected the accuracy of quantitative iodine measurements, it is unlikely to have significantly affected the percentage of salt samples reported as above and below 15 ppm iodine. The consistency of the findings, including in surveys where it is known that external quality assurance procedures were implemented, provides confidence in the overall findings and conclusion of the present study.

The findings in the present study demonstrate that the RTK under 'real life' conditions do not provide a reliable household coverage estimate of adequately iodized salt. The analysis confirms that the current version of the RTK as a simple acid-starch solution is an imprecise tool that has been inappropriately used in the past to quantify the content of iodine in salt rather than merely detect its presence. Many household and school surveys carried out in the past used only RTK to assess the adequacy of iodine content in salt. The global databases include these estimates and it is impossible to determine the extent to which this has led to biased coverage estimates for salt with adequate iodine. Our findings also illustrate that the RTK typically underestimated the coverage of salt with any iodine when compared with quantitative methods, while it overestimated the coverage of salt with adequate iodine. In our view, it would be prudent to use the RTK only for assessing the presence of any iodine in salt and, in addition, to use a quantitative method to assess the iodine content in salt. For practical purposes, a systematic sub-sample of survey households could be drawn for collection of salt for quantitative analysis from which an estimate of the proportion of households consuming adequately iodized salt could be made. While RTK testing was particularly useful when salt iodization was first introduced during the 1990s, as these strategies mature, programmes now require quantitative information and it is necessary to assess the proportion of non-iodized salt as well as various levels of iodine content in salt, both for the lower and upper levels of iodization. Having quantitative information will equip programme managers with the right information to make decisions on corrective action. There are an increasing number of technologies available that will enable quantitative assessment of the iodine content of salt in the field. A recent analysis of the laboratory performance parameters of five technologies, including the WYD, found that the iCheck ${ }^{\circledR}$ and I-Reader ${ }^{\circledR}$ showed the most consistent performance and ease of use, and a newly developed paper-based method (saltPAD) holds promise if further developed ${ }^{(19)}$. Any tool may be subject to misuse in the field, but the relative lack of subjectivity in the use of these new tools may render them more reliable than RTK in routine salt monitoring. In any case, their feasibility and cost-effectiveness in the field will need to be determined before being widely recommended.

\section{Conclusion}

The RTK is not suited for assessment of the coverage of adequately iodized salt in field surveys and should be used only for detecting whether salt is iodized, or not.

The findings from the present study lead to the following recommendations for population-based assessments, such as MICS, DHS, Household Income and Economic Surveys, and household- or school-based nutrition surveys, designed to obtain household coverage estimates of iodized and adequately iodized salt:

1. In field surveys, RTK should be used only for obtaining a coverage estimate of iodized salt (any iodine).

2. It is important to keep in mind, however, that even this coverage estimate has its limitations as evidenced by the finding that the overall accuracy of the RTK achieved $>90 \%$ in less than half of the twenty-five surveys in the present study. The need for caution is also supported by the starkly different RTK performance findings in Ghana.

3. Validated quantitative methods on a full or substantial sub-sample of household salt specimens are required if the survey's objective is to obtain a coverage estimate of adequately iodized salt.

4. The combination of these two approaches - RTK to assess the coverage of salt with any iodine and a quantitative tool to assess the coverage of adequately iodized salt - will provide programme managers with more reliable data to track programme performance.

5. Further standardization is needed of the use of RTK in household surveys including training and standardization exercises to limit measurement errors, as well as its correct application for the type of fortificant used.

\section{Acknowledgements}

Financial support: This work was supported by UNICEF and the US Agency for International Development (USAID). USAID had no role in the design, analysis or writing of this article. Conflict of interest: None. Authorship: J.G., F.v.d.H. and J.K. were involved with the design, conceptualization, data analysis, and preparation and editing of the manuscript. K.C., R.H. and A.T. were involved with the conceptualization, review of data, and preparation and editing of the manuscript. Ethics of buman subject participation: Not applicable. 


\section{References}

1. Zimmermann MB, Jooste PL \& Pandav CS (2008) Iodinedeficiency disorders. Lancet 372, 1251-1262.

2. Aburto N, Abudou M, Candeia V et al. (2014) Effect and Safety of Salt Iodization to Prevent Iodine Deficiency Disorders: A Systematic Review with Meta-Analyses. Geneva: WHO; available at http://www.who.int/nutrition/publications/micronutrients/ effect_safety_saltiodization/en/

3. World Health Organization (2014) Fortification of Food Grade Salt with Iodine for the Prevention and Control of Iodine Deficiency Disorders. Guideline. Geneva: WHO.

4. World Health Organization (1994) World Summit for Children - Mid-decade goal: Iodine Deficiency Disorders (IDD). UNICEF-WHO Joint Committee on Health Policy Special Session, Geneva, 27-28 January 1994, Agenda Item 2.2.7, JCHPSS/94/2.7. Geneva: WHO.

5. World Health Organization, UNICEF \& International Council for Control of Iodine Deficiency Disorders (2007) Assessment of Iodine Deficiency Disorders and Monitoring Their Elimination: A Guide for Program Managers, 3rd ed. Geneva: WHO; available at http://whqlibdoc.who.int/ publications/2007/9789241595827_eng.pdf

6. UNICEF (2015) The State of the World's Children 2015: Reimagine the Future. New York: UNICEF; available at http:// sowc2015.unicef.org/

7. Pearce EN, Andersson M \& Zimmermann MB (2013) Global iodine nutrition: where do we stand in 2013? Thyroid $\mathbf{2 3}$, 523-528.

8. Rohner F, Zimmermann MB, Jooste P et al. (2014) Biomarkers of nutrition for development - iodine review. J Nutr 144, issue 8, 1321S-1342S.

9. Sullivan KM, Houston R, Gorstein J et al. (editors) (1996) Rapid salt testing kits. In: Monitoring Universal Salt Iodization Programmes, pp. 80-85. New York: UNICEF, Programme Against Micronutrient Malnutrition (PAMM), Micronutrient Initiative (MI), International Council for Control of Iodine Deficiency Disorders (ICCIDD) and WHO.
10. Jooste PL \& Strydom E (2004) An Evaluation of the Accuracy and Stability of Rapid Iodine Test Kits Produced in Different Countries. Cape Town: MRC Nutritional Intervention Research Unit Technical Report.

11. World Health Ogranization \& UNICEF (2004) Report of the Technical Consultation to Assess Rapid Test Kits Designed to Monitor Salt Iodine Content. New York: UNICEF.

12. Dearth-Wesley T, Makhmudov A, Pfeiffer CM et al. (2004) Fast and reliable salt iodine measurement: evaluation of the WYD Iodine Checker in comparison with iodometric titration. Food Nutr Bull 25, 130-136.

13. Nair S, Sharma SK, Singh MB et al. (2010) Validity of Spot Testing Kit in the Assessment of Iodine Content in Salt - A Multi-Site Study. New Delhi: All-India Institute of Medical Sciences.

14. Pandav CS, Arora NK, Krishnan A et al. (2000) Validation of spot testing kits to determine iodine content in salt. Bull World Health Organ 78, 975-990.

15. Aquaron R (2000) Iodine content of non-iodised salts and iodised salts obtained from retail markets worldwide. In 8th World Salt Symposium vol. 2, pp. 935-940 [R Geertman, editor]. New York: Elsevier.

16. Altman DG (2000) Diagnostic tests. In Statistics with Confidence: Confidence Intervals and Statistical Guidelines, 2nd ed., pp. 105-119 [DG Altman, D Machin, TN Bryant et al., editors]. Bristol: BMJ Books.

17. Kapil U, Nayar D \& Goindi G (1994) Utility of spot testing kit in the quantitative estimation of iodine content in salt. Indian Pediatr 31, 1433-1435.

18. Reitsma JB, Glas AS, Rutjes AWS et al. (2005) Bivariate analysis of sensitivity and specificity produces informative summary measures in diagnostic reviews. J Clin Epidemiol 58, 982-990.

19. Rohner F, Kangambèga MO, Khan $\mathrm{N}$ et al. (2015) Comparative validation of five quantitative rapid test kits for the analysis of salt iodine content: laboratory performance, user- and field-friendliness. PLOS ONE 10, $\mathrm{e} 0138530$. 